\title{
ТЕОРЕТИЧЕСКИЕ И КОНЦЕПТУАЛЬНЫЕ ПОДХОДЫ К МОДЕЛИРОВАНИЮ ЭКОНОМИЧЕСКОЙ ДИНАМИКИ В КОНТЕКСТЕ ЦИФРОВОЙ ТРАНСФОРМАЦИИ
}

\author{
О.Н. Поддубная"
}

В контексте современных экономических теорий эволюторно описаны понятия «автоматизация», «цифровизация», «цифровая трансформация», «цифровая экономика» и их взаимосвязи. Сделан акцент на алгоритмически-цифровой парадигме новых экономических отношений. Выделены важные особенности цифровых ресурсов и технологий. На основе синтеза современных идей экономической кибернетики, институционального и системного подходов выносится на обсуждение научная гипотеза о модели иерархической триады «экономический процесс - экономическая система - экономическая среда». В рамках эволюционной экономической теории в модель иерархической триады интегрирована экономическая динамика, генерируемая внешними и внутренними взаимодействиями процессов экономической системы. Предлагаются новые теоретико-методологические основы к возможным подходам моделирования экономической динамики в условиях цифровой трансформации.

Ключевые слова: цифровизация, цифровая трансформация, цифровая экономика, экономическая динамика, институционально-эволюционное направление.

JEL-классификация: B15, B16, C65, О10.

DOI: $10.46782 / 1818-4510-2020-4-79-90$

Материал поступил 24.11.2020 2.

Сегодня в кругах бизнеса, науки и политики широко обсуждаются термин «цифровая трансформация» и родственные понятия, предлагается множество как авторских, так и коллективных, монодисциплинарных и синергетических определений. В эпоху глобальной цифровизации бизнес трансформирует свою структуру, стратегии развития, корпоративную культуру, системы продаж, управление командой и процессами в целом, что порождает радикальные изменения, когда создаются абсолютно новые продукты, сервисы и целые отрасли. Государственная политика реагирует на вызовы быстро развивающегося информационного общества, формируя «цифровые повестки» национальных и транснациональных инициатив, выявляя проблемы и формулируя стратегии развития, создавая новую инфраструктуру для представителей бизнеса, исследователей, разработчиков. В результате многостороннего научного анализа современных экономических тенден- ций образуется новый понятийный аппарат, изменяются методологические принципы, зарождаются и развиваются новые направления экономической теории.

Авторы многих научных публикаций предлагают обзор уже существующих определений понятия «цифровая экономика», в основу которых положен ресурсный, поточный, структурный или бизнес-ориентированный подход ${ }^{1}$. Р. Бухтом и Р. Хиксом (2018) проанализированы различные определения цифровой экономики с точки зрения их развития во времени; итогом анализа является представленная трехуровневая модель, во вложенной структуре которой выделяются цифровой сектор, цифровая экономика, а на внешнем уровне - цифровизированная экономика. Большинство ученых сходятся во мнении, что унифицированное понятие циф-

${ }^{1}$ Гохберг Л.М. (Ред.) 2019. Что такое цифровая экономика? Тренды, компетенции, измерения: доклад НИУ ВШЭ. URL: https://issek.hse.ru/data/2019/04/10/ 1174567204/Цифровая_экономика.pdf

* Поддубная Олеся Николаевна (poddubnaya.o@tut.by), кандидат физико-математических наук, доцент, Белорусский государственный экономический университет (г. Минск, Беларусь). 
ровой экономики пока еще отсутствует, «само по себе это не делает измерение цифровой экономики сложным, однако затрудняет сравнительный анализ» (Там же).

Материал представленной статьи изложен в двух разделах. В первом разделе ретроспективно описываются ключевые технические, технологические, управленческо-организационные инновации, определяющие основные этапы цифровизации с особенностями и взаимосвязями. Второй раздел посвящен новому подходу в рамках институционально-эволюционного направления формализации зависимостей в обобщенной модели производственных отношений для описания таких ключевых свойств цифровой среды, как универсальность и динамизм.

\section{Алгоритмически-цифровая парадигма новых әкономических отношений}

Отправной точкой любого исследования является изучение базовых понятий в ретроспективе. Чтобы глубже понять суть предмета исследования, необходимо начать с предпосылок его возникновения. Основные научно-технические достижения, позволившие обозначить нынешний исторический период как «цифровую эпоху», на наш взгляд, следующие. В 1928 г. инженером-электронщиком Г. Найквистом впервые была указана частота, равная удвоенной предельной частоте исходного сигнала. Она послужила основой теоремы, независимо доказанной в 1933 г. В. Котельниковым и в 1949 г. К. Шенноном, в которой любой аналоговый (непрерывный) сигнал может быть восстановлен с какой угодно точностью по цифровому сигналу (дискретным отсчетам). После завершения в 1973 г. судебного процесса между корпорацией Sperry Rand и компанией Honeywell за авторство изобретения электронной вычислительной машины широкой общественности стало известно, что в ЭВМ ENIAC, которая считалась до судебного разбирательства первым электронным цифровым компьютером, созданным Дж. Мокли и Дж. Эккертом еще в далеких 40-х годах, использованы конструктивные особенности компьютера АВС Дж. Атанасова. Первый прототип компьютера ABC (Atanasoff-Berry Computer), pa- ботанный на основе двоичной системы счисления и алгебры Дж. Буля (основные математические труды им созданы в середине XIX в.), продемонстрирован еще в 1939 г., и его целью было решение системы линейных уравнений с 29 переменными. В 1942-1945 гг. инженер К. Цузе активно работал над созданием собственного языка программирования, названного им Plankalkül, что в переводе с немецкого означало «план вычислений». Язык имел многие свойства высокоуровневого (наличие подпрограмм; создание циклов; работа с массивами и списками). В 1969 г. американскими военными осуществлено объединение автономных компьютеров, а в 1970 г. реализованы основные принципы управления сетью с равноправными узлами ARPANET, которая стала прообразом современного интернета. В 1975 г. состоялась презентация первой сверхскоростной вычислительной машины Cray-1 (суперкомпьютера с поддержкой векторных операций), спроектированной С. Крэйем и созданной компанией Cray Research Inc. (в 1976 г. она была приобретена Национальным Центром Атмосферных исследований США).

Прошло чуть меньше века, что по меркам истории является крайне незначительным временным периодом, - произошли кардинальные изменения цифровых устройств и технологий, а также задач, которые человечество пытается с их помощью решать, в том числе в экономике.

Впервые термин цифровая экономика (digital economy) появился в 1995 г. в книге «Электронно-цифровое общество: Плюсы и минусы эпохи сетевого интеллекта» канадского исследователя, преподавателя и общественного деятеля Д. Тапскотта, а в широкое употребление его ввел американский ученый Н. Негропонте 2 . В своей книге Д. Тапскотт дает цифровой экономике следующее лаконичное определение: это экономика, базирующаяся на использовании информационных компьютерных технологий (Tapscott, 1995). Следует отметить, что Д. Тапскотт подошел к исследованию проблемы с позиций современного институционализма. На основе теории фирмы

\footnotetext{
A. Knopf.
} 
Р. Коуза (1993) и анализа тенденций изменения трансакционных издержек им спрогнозированы почти все тренды современного бизнеса в новом цифровом пространстве. Отметим, что сегодня нет устоявшейся трактовки термина «цифровая экономика», продолжается его развитие и поиск места в современной парадигме социально-экономического развития. Наряду с понятием «цифровая экономика» следует обратиться к родственным понятиям «автоматизация», «цифровизация» и «цифровая трансформация», изучить их взаимосвязи в контексте современных экономических теорий.

Хронологически первым глобальным этапом «оцифровки» бизнеса, производства и общества можно считать автоматизацию в широком смысле слова. Автоматизация процесс внедрения и эксплуатации совокупности работающих средств (программ и устройств), обеспечивающих минимизацию рутинных, часто повторяющихся операций (в том числе управленческих), оптимизацию трудовых и производственных ресурсов с целью наращивания продуктивности и эффективности всех бизнес-процессов. Результатом автоматизации является замена ручного труда роботизированными устройствами и перевод текущих процессов в электронную форму без учета методологии гибких изменений. Автоматизация направлена на решение рутинных задач одного или смежных бизнес-процессов, таких как кадровый учет, материальное планирование, электронный документооборот и др. Она ориентирована на обработку типовых ситуаций, нестандартные задачи решаются вручную и подлежат алгоритмизации постфактум.

Изобретение емких и дешевых носителей, а также высокоскоростных каналов передачи информации стало триггером следующего этапа, который принято называть цифровизацией. Цифровизащия - процесс создания цифровых ресурсов и технологий, базирующихся на алгоритмическом сборе, анализе и обработке больших массивов данных, а также генерации подобных данных. Она предполагает непрерывное управление данными об объекте на протяжении всего жизненного цикла с использованием электронного двойника реального объекта и циф- рового макета производства ${ }^{3}$. Цифровизация позволяет осуществлять опережающее управление с применением инструментов предиктивной аналитики для прогнозов будущих ситуаций, в том числе нетривиальных, а также рассчитывать оптимальные отклики на них. Мощнейшим цифровым ресурсом экономики сегодня становятся кросс-функциональные платформы (список наиболее динамично растущих международных брендов возглавляют компании-платформы: Microsoft, Apple, Amazon, Google, Facebook, Tencent, Alibaba). Их влияние и функционал нарастают вследствие развития технологий искусственного интеллекта, в основе которых лежат алгоритмы генерации данных, облачных вычислений (более дешевые технологии кластерных вычислений как альтернатива дорогим суперкомпьютерам) и машинного обучения. «Цифровые платформы упрощают осуществление операций, формирование связей и обмен информацией» ${ }^{4}$. Благодаря сетевым связям платформенная система меняет традиционную линейную конвейерную модель создания и распространения ценности, заменяя интуицию посредников в продвижении товара на рынок сигналами самого рынка, поступающими по каналам обратной связи от потребителей. Платформенная модель бизнеса сместила акцент управления с внутренних ресурсов на внешние, объединила логику конкуренции с логикой кооперации.

Уменьшение стоимости цифровых устройств и каналов связи позволило потребителям стать производителями новых цифровых товаров и технологий и успешно конкурировать с профессионалами ${ }^{5}$, в том числе в отраслях, традиционно считавшихся офлайновыми. Феномены краудсорсинга $^{6}$, гиганомики ${ }^{7}$ меняют представление о взаимодействии экономических агентов.

\footnotetext{
${ }^{3}$ Grieves M. 2017. Digital twin: Manufacturing excellence through virtual factory replication. Florida Institute of Technology. URL: http://alterozoom.com/ru/documents/42557.html

4 URL: https://unctad.org/en/PublicationsLibrary/ der2019_overview_ru.pdf

5 Речь идет о цифровом феномене «потребитель как производитель».

${ }^{6}$ Википедия - самый известный проект, начатый и развивающийся с помощью «коллективного разума как инструмента развития бизнеса» (Хау, 2012); является примером бесплатной продукции, которая создает добавленную стоимость.

7 Gig-economy в литературе часто называют «экономикой свободного заработка».
} 
Масштабная, повсеместная и динамическая диффузия цифровых ресурсов и технологий начала менять структуру экономики, ознаменовывая переход к цифровой трансформации.

Цифровая трансформация - процесс комплексного использования цифровых ресурсов и технологий во всех сферах человеческой деятельности, результатом которого является кардинальное изменение социальных, политических и бизнес-моделей для формирования новой цифровой среды, дополняющей нашу реальность. Отличительной особенностью цифровой трансформации по сравнению с предыдущими промышленными революциями, обусловленными исключительно появлением новых технологий, является скорость и всеобъемлющий характер (ввиду их универсальности) освоения цифровых технологий (так называемые «сквозные» технологии, осуществляющие межпроцессную «бесшовную» интеграцию данных и продуктов). В реальном секторе происходит масштабное дополнение, а в некоторых случаях - и замена продукта сервисом (феномен сжатия или даже исчезновения традиционных рынков), формируется так называемая «сервисная экономика». Сферу услуг трансформируют технологии уберизации и совместного потребления, что приводит к сокращению трансакционных издержек ${ }^{8}$ и созданию «экономики взаимопомощи». Финансовый сектор претерпевает глобальные изменения с внедрением принципиально новых по своей сути технологий, одна из которых (криптовалюта $\left.^{9}\right)$ при наличии политической воли и решений по формированию инфраструктуры и правовой среды может стать прорывной инновацией сектора. Легкость копирования, передачи и распространения информации в цифровом формате ведет к потере ее конкурентоспособности как товара, когда потребитель не готов много платить за продукт, который не является дефицитным. Это влечет за собой проблемы ценообразования и защиты ин-

\footnotetext{
${ }^{8}$ Издержки поиска информации, измерений, ведения переговоров.

9 Разновидность цифровой монеты на основе технологии блокчейн, генерирующейся криптографическим алгоритмом.
}

формации, и, как следствие, остро встают вопросы окупаемости инвестиций, например, в медиапродукты, разработку программного обеспечения.

Приоритетным направлением экономической политики в условиях цифровой трансформации становится формирование цифровой государственной экосистемы, национальной киберинфраструктуры. Сегодня от разрабатываемых и принимаемых стандартов и мер регулирования в этой сфере зависит если не все, то очень многое. Экономия на издержках ex-ante, а также несвоевременность или поспешность в принятии норм могут привести к очень значительным издержкам ex-post. Показательным примером этому служат огромные издержки правообладателей из-за «пиратства» в результате цифровой трансформации медиа до введения авторского и смежного права. Огромные усилия прилагаются странами-лидерами в правовом и техническом обеспечении распознавания и пресечения создания и распространения цифрового вредоносного контента, для укрепления межгосударственного сотрудничества в области кибербезопасности. В десятках различных стран мира разрабатываются и реализуются национальные и межгосударственные программы по стимулированию процессов цифровой трансформации. В 2011 г. Германия представила широко известную государственную стратегию «Industrie 4.0», в 2014 г. в Японии опубликована «Smart Japan ICT Strategy», в КНР в 2015 г. анонсирована национальная концепция «Internet Plus», в 2017 г. Великобритания приняла цифровую стратегию «UK Digital Strategy 2017», Pocсия сформировала в 2017 г. программу «Цифровая экономика Российской Федерации» ${ }^{10}$, в Республике Беларусь подписан Декрет «О развитии цифровой экономики» ${ }^{11}$. Для выработки общих подходов и мер по стимулированию цифровых инноваций были выработаны «цифровые повестки»: в 2010 г. «Цифровая повестка для Европы», 2017 г. - Решение Высшего Евразийского экономического совета «Об Основных направлениях реализации цифровой повестки Евразийского эко-

10 URL: http://static.government.ru/media/files/ 9gFM4FHj4PsB79I5v7yLVuPgu4bvR7M0.pdf

${ }^{11}$ URL: https://pravo.by/document/?guid $=12551 \& \mathrm{p} 0=$ $\operatorname{Pd} 1700008 \& \mathrm{p} 1=1 \& \mathrm{p} 5=0$ 
номического союза до 2025 года». Цифровая трансформация охватила весь мир ${ }^{12}$, но нигде не завершена, поэтому чей-то успешный опыт невозможно просто скопировать - необходим поиск своих идей и путей.

Всеобъемлющие современные цифровые трансформационные процессы направлены на принципиальное изменение структуры экономики, производительных сил и производственных отношений, на формирование новой цифровой среды - всех процессов, поддающихся формализации (превращению в логические схемы) и дальнейшей оцифровке. Ключевой особенностью этой среды становится глобализация и масштабируемость производственных возможностей «платформенной экономики» для качественного, доступного и своевременного удовлетворения персонифицированных потребностей (создание потребительской ценности). Уникальность нынешней технологической революции в том, что никогда ранее подрывные инновационные технологические процессы не посягали на создание искусственной среды, экосистемы, встроенной в реальность. Огромным толчком в формировании цифровой среды послужили принципы транспарентности, концепция открытых систем и программного обеспечения с открытым кодом (Open Source).

В результате цифровой трансформации стираются границы между отраслями, формируются новые трансграничные технологические альянсы, меняется представление о конкуренции и активах, что кардинально меняют принципы традиционной хозяйственной деятельности человека, сложившейся в «доцифровой эре».

Цифровая экономика - хозяйственная деятельность человечества, а также система отношений, связанных с производством, распределением, обменом и потреблением товаров и услуг в современной цифровой среде. Новым базисом цифровой экономики становится алгоритмически-цифровая парадигма экономического развития, реализующая в макроэкономическом плане цели устранения дисбаланса между безграничностью потребностей и ограниченностью ресурсов, опреде-

12 Цифровая экономика имеет неодинаковое влияние в странах глобального Севера и глобального Юга. Распределение внутри регионов также неравномерно. Темпы роста цифровой экономики особенно высоки в странах глобального Юга (Бухт, Хикс, 2018). ленные еще экономистами классической школы, на основе принципиально новых форм взаимодействий. На сегодняшний день на всех этапах хозяйственной деятельности разворачивается борьба алгоритмов: фактическое конкурентное преимущество получает тот, кто строит бизнес на использовании более прогрессивного цифрового ресурса, а конкурентный потенциал можно оценивать через способность верного расчета времени совершенствования имеющейся цифровой технологии или перехода на новую в соответствии с этапом жизненного цикла бизнеса.

В цифровой экономике по Тапскотту основным драйвером прогресса становятся знания, в том числе формализованные, позволяющие человеку создавать, преобразовывать и непрерывно управлять цифровой средой, которая в отличие от реальной среды является производной интеллекта, мыслительной деятельности человека. Цифровая грамотность должна стать основным императивом цифровой экономики. Выступление академика А. Ершова с докладом «Программирование - вторая грамотность» на 3-й Всемирной конференции ИФИП (Международной федерации по обработке информации) по применению ЭВМ в обучении, прошедшей в июле 1981 г. в Лозанне, получило широкий резонанс, название же доклада в то время многие посчитали провокационным и фантастичным. Сегодня креативные представители нового класса ИКТ-специалистов не согласятся лишь со словом «вторая» в вышеупомянутом названии доклада, которое со временем стало девизом «элитарных» программистов «солдат технической революции, обладающих революционным мышлением» (по словам А. Ершова $)^{13}$. Доля работающих в секторе ИКТ от общего числа занятых в Европейском союзе в 2016 г. составляла $3,7 \%$ (лидеры Финляндия 6,6\%, Швеция 6,3\%, Эстония 5,3\% $)^{14}$. Этот показатель на 2017 г. составлял 4,6\% в Корее, 3,1\% в США, 1,7\% в России ${ }^{15}$. Национальный статистический

\footnotetext{
${ }^{14}$ URL: https://ec.europa.eu/eurostat/cache/infographs/ ict/bloc-1c.html

15 Россия: от цифровизации к цифровой экономике. URL: http://stolypin.institute/institute/rossiya-ot-tsifrovizatsiik-tsifrovoy-ekonomike
} article

13 URL: http://ershov.iis.nsk.su/ru/second_literacy/ 
комитет Республики Беларусь данный показатель для нашей страны оценил 2,4\% в 2017 г., 2,7\% в 2018 г. и 2,9\% в 2019 г. ${ }^{16}$ Рынок труда ощущает кадровый голод в бизнес-аналитиках, системных архитектоpax, специалистах по мультимедийным технологиям, технических ИТ-специалистах, специалистах по информационной безопасности, менеджерах ИТ-проектов. Поэтому цифры, отражающие долю работающих в секторе ИКТ, будут ежегодно увеличиваться. А как же другой, большей, части населения, которая не в ИКТ-секторе, встраиваться и приспосабливаться к цифровой среде, усложняющейся день ото дня, как найти свое место на переформатированном цифровой трансформацией рынке труда с такими необычными профессиями, как оператор беспилотников, юрист-консультант по работе в сети, цифровой маркетолог, инфостилист, тайм-брокер, форсайтер? Еще в 1931 г. Дж. Кейнс говорил о явлении технологической безработицы, когда «открытие способов экономного использования труда опережает темпы выявления новых применений труда» ${ }^{17}$. Для тех, кто будет желать использовать «полный функционал» новых технологий для построения личной бизнес-модели, концепция «обучение через всю жизнь» должна стать аксиомой как для поколения $\alpha$ с цифровым ДНК, для которых цифровая среда изначально станет не просто технологией, а средой жизни, формирующей личность. В новой цифровой реальности мы начинаем наблюдать трансформацию процесса обучения, когда традиционные образовательные технологии активно дополняются цифровыми образовательными ресурсами, главными особенностями которых являются интерактивность, геймификация, новая корпоративная архитектура и культура.

Наряду с интеллектуализацией ключевой характеристикой процессов цифровой трансформации является их высочайший динамизм. Вернемся к вопросу окупаемости инвестиций. Одна из особенностей инвестирования в цифровые технологии -

${ }^{16}$ URL:ttps://www.belstat.gov.by/ofitsialnaya-statistika/ makroekonomika-i-okruzhayushchaya-sreda/informatsionnotelekommunikatsionnye-tekhnologii/tsifrovaya-ekonomika/ Macmillan. временные риски. Первый аспект этого риска - низкая скорость создания технологии, когда реальные трудозатраты, временные затраты слишком велики и к моменту старта созданной технологии рынок уже не испытывает в ней потребности, имея качественную альтернативу. Второй аспект кроется в динамизме цифровой среды, что отражается в частой неактуальности слишком долго разрабатываемых технологий, которые успевают устареть еще до выхода на рынок. Для цифровых технологий в кривой жизненного цикла крайне короток временной период от научно-прикладных поисковых исследований до коммерческого применения. Поэтому свои цифровые стратегии компаниям приходится постоянно актуализировать. Речь, конечно же, не идет о глобальных фундаментальных проектах, таких как, например, квантовые технологии (квантовые вычисления, квантовые компьютеры, квантовые сенсоры, квантовые коммуникации), обещающие настоящий прорыв, новую техническую революцию. Финансируются эти проекты как по целевым государственным программам, так и за счет инвестиций со стороны крупных частных компаний, в которых создаются внутренние научно-исследовательские подразделения, а также инвестиций, привлекаемых через венчурные фонды.

Цифровая трансформация и родственные понятия широко используются в социально-экономических исследованиях. Однако масштабность применения означает накопление пока достаточно разрозненных версий методологии анализа проблемы, а глубокая исследованность вопроса находится, на наш взгляд, в начальной стадии теоретического осмысления и становления.

\section{Процессно-системный подход в моделировании современной экономической динамики}

Экономический рост - это важнейшая характеристика экономического развития. Особенности современных производительных сил, формирующих цифровую среду, должны найти свое отражение в моделях экономического роста, являющихся теоретическим инструментом количественного описа- 
ния структурных сдвигов, происходящих в экономике. Среди наиболее популярных и хорошо изученных подходов количественного анализа в экономике выделяются методологии обобщающих показателей, индексов и индикаторов, разработанные на основе разнообразных статистических методов ${ }^{18}$. Еще одним направлением количественных методов обработки результатов наблюдения в рамках пассивного научного эксперимента для целей прогнозной аналитики является экономико-математическое моделирование, которое стали активно развивать ученые классического и неоклассического направлений, начиная с маржиналистов второй волны (французская, немецкая, английская школа). При разработке моделей исследователи сталкиваются, во-первых, с проблемой адекватности выбранных математических методов для изучения с их помощью экономического явления, а во-вторых, с необходимостью разумного определения уровня сложности математического аппарата для целей анализа. С одной стороны, слишком простой математический инструментарий может не позволить адекватно описать изучаемый многофакторный быстро изменяющийся экономический процесс. С другой стороны, огромное количество разделов современного математического аппарата пока не нашло своего применения в экономических исследованиях ввиду кажущейся сложности или из-за его несоответствия доминирующим парадигмам экономической теории.

Безусловным прорывом в истории экономической мысли стали в последней трети XIX в. новаторские идеи маржиналистов, использовавших математический аппарат ${ }^{19}$ анализа, в котором предпочли отказаться от причинно-следственного подхода в пользу функционального для выявления равновесия в хозяйственной системе (в масштабе фирмы)

18 Для проведения статистических измерений по этапам жизненного цикла технологий приводится операционализированное определение цифровой экономики: «цифровая экономика - деятельность по созданию, распространению и использованию цифровых технологий и связанных с ними продуктов и услуг». Гохберг Л.М. (Ред.) 2020. Индикаторы иифровой экономики: 2020: стат. сборник. Москва: НИУ ВШЭ. URL: https://issek.hse.ru/mirror/pubs/ share/387609461.pdf

${ }^{19}$ Использование предельного анализа для нахождения предельной полезности и предельных издержек, а также эластичности спроса и предложения; интерпретация тер- при условии рационального поведения хозяйственных субъектов. Маржиналисты сделали акцент на статических задачах для краткосрочных периодов, на протяжении которых факторы не успевают измениться. О неадекватности статичной оптимизационной модели задаче исследования поведения экономических агентов в экономике как сложной системе говорили Й. Шумпетер ${ }^{20}$, Т. Веб$л е^{21}$, А. Маршалл ${ }^{22}$, Ф. Нортроп ${ }^{23}$, Г. Тинтер $^{24}$, а также другие исследователи австрийского, институционального, западного марксистского, неокейнсианского, эволюционного направлений, или так называемых неортодоксальных течений ${ }^{25}$ экономической теории. Концепция динамизма систем коренным образом меняет подход к их изучению, позволяя устанавливать факты и закономерности, которые иначе оказались бы необнаруженными. Без анализа динамики происходящих процессов в экономической системе было бы невозможным охарактеризовать и ее равновесное состояние, имеющее решающее значение для оценки функционирования системы и выяснения возможности ее длительного существования. В этом плане достаточно перспективной выглядит концепция эволюционного экономического развития. Эволюционная теория рассматривает развитие как развертывающуюся последовательность событий через призму процессов долгосрочных поступательных изменений. Развитие системы интерпретируется как совокупный результат действия поддающихся

\footnotetext{
мина «рациональность» через максимальную полезность индивида и его математическая формализация с помощью максимума целевой функции (задача на условный оптимум); применение дифференциальных уравнений для решения задачи о равновесной цене (модель Л. Вальраса); разработка теории производственных функций.

${ }^{20}$ Шумпетер Й. 2007. Теория экономического развития. Москва: Эксмо.

${ }^{21}$ Veblen T. 1898. Why Is Economics not an Evolutionary Science? The Quarterly Journal of Economics. Vol. 12. No 4. PP. 373-397.

${ }_{22}$ Маршалл А. 1983. Принцииы политической экономии. Т. 1. Москва: Прогресс.

${ }^{23}$ Northrop F.S.C. 1941. The Impossibility of a Theoretical Science of Economic Dynamics. The Quarterly Journal of Economics. Vol. 56. PP. 1-17.

${ }^{24}$ Tintner G. 1941. The Theory of Choice under Subjunctive Risk and Uncertainty. Econometrica. Vol. 9. P. 298-311.

${ }^{25} \mathrm{~B}$ современной экономической теории наблюдается тенденция усиления роли неортодоксальных экономических течений, являющихся альтернативой ортодоксальной неоклассике или, как ее называют в научной литератуpe, экономической теории мэйнстрима.
} 
осмыслению динамических процессов: от известных или предполагаемых состояний в прошлом к настоящим и будущим. При данном подходе акцентируется внимание на динамических аспектах экономических исследований: «..если экономика пребывает в состоянии непрекращающегося движения, то нормативные свойства, которые ассоциируются с конкурентным равновесием, теряют всякий смысл, как и описание поведения в терминах равновесия»; если «подразумевается динамический контекст, в котором предпочтения, ресурсы и технологии со временем претерпевают не до конца предсказуемые изменения, оптимум аллокации должен быть подвижным» (Нельсон, Уинтер, 2000). Более радикальное утверждение: «экономика как живая система, эволюционирующая к большей сложности и разнообразию производства и потребления, никогда не бывает в состоянии равновесия. Более того, она все больше удаляется от этого состояния» (Мясникович, Глазьев, 2020) ввиду того, что «нестабильность и неравновесие являются не менее фундаментальными свойствами экономических систем, чем стремление к достижению и поддержанию равновесия» (Горев, Макарова, Сергеева, 2008). Как отмечает Д. Фролов (2019), «эволюционный анализ одно из самых значительных достижений мировой экономической мысли за всю ее историю».

Вторая волна критики ортодоксального направления экономической теории инициирована представителями институционального направления ${ }^{26}$ как аргументированное отрицание постулата о неуправляемости рыночных сил вследствие свободной конкуренции в классическом и неоклассическом учении. «Первая аксиома доктрины экономического равновесия, лежащая в основе доминирующей сегодня в экономической теории неоклассической парадигмы, декларирует принцип свободной конкуренции. Согласно ему, в экономике субъекты хозяйствования (или «экономические агенты») абсолютно автономны и независимы от других участников рынка, никто из них не может влиять на цены, которые складываются стихийным образом в результате

${ }^{26}$ Среди ярких представителей нового институционализма отметим Р. Коуза (1993) и Д. Норта (1997). соотношения спроса и предложения. В реальности свободной конкуренции никогда и нигде не наблюдалось. Формирование рыночной экономики происходило в условиях многочисленных монополий и государственных ограничений. Современная экономика характеризуется олигополистической конкуренцией и системным государственным регулированием» (Мясникович, Глазьев, 2020). Сложные экономические явления являются не закрытыми саморазвивающимися системами, а открытыми поливариантными, гибридными, подверженными процессу внешнего управления соответствующего экономического окружения. Изучение управляемых экономических систем не в статическом состоянии, а в их движении и развитии - основная задача экономической кибернетики, достаточно молодой науки ${ }^{27}$, успешно использующей методы научной интеграции, широкого обобщения, системного анализа. Инструментальным ядром кибернетики по праву считают теорию автоматического управления (регулирования) - математического направления, особенно динамично развивавшегося во второй половине XX в. американскими и советскими математиками ${ }^{28}$.

Таким образом, как отмечают многие исследователи, адекватное описание и изучение современной экономической реальности требует разработки новой парадигмы в экономической науке в ходе синтеза современных идей экономической кибернетики, институционального, эволюционного, системного (Kornai, 1998) ${ }^{29}$ и других направлений

27 В 1948 г. вышла известная книга «Кибернетика, или управление и связь в животном и машине» Н. Винера, считавшегося родоначальником кибернетики как науки об управлении, т. е. целенаправленном воздействии на системы, а также о процессах обработки информации и их автоматизации. Сам Н. Винер не раз упоминал, что в области математического описания аналогичные результаты независимо от американских ученых получил российский математик А. Колмогоров. Кибернетический подход к изучению экономических систем впервые стал применять С. Бир, но только лишь к концу XX в. понятийный, концептуальный и математический аппарат кибернетики стал эффективно использоваться для описания, моделирования и прогноза социально-экономических систем.

28 Белорусская научная математическая школа внесла существенный вклад в разработку качественной теории оптимальных процессов и теории оптимального управления. Габасов Р.Ф., Кириллова Ф.М. 1971. Качественная теория оптимальных процессов. Москва: Наука; Gabasov R., Kirillova F., Prischepova S. 1995. Optimal feedback control. London: Springer. 
экономической теории. От предложенных в рамках ортодоксальных течений экономикоматематических методов анализа систем (методы оптимальных решений, эконометрические методы, производственные функции) при условии, что структура взаимного влияния неизвестных факторов не претерпевает существенных изменений на исследуемых временных отрезках, сегодня «не приходится ожидать ни достоверных оценок, ни полезных рекомендаций» (Мясникович, Глазьев, 2020). Ввиду разработки новых направлений современной экономической теории необходимо актуализировать аппарат экономико-математического моделирования, осуществлять научный поиск новых концептуальных и алгоритмических подходов к созданию адаптивных моделей стратегического управления для многоаспектного анализа современного экономического развития.

На наш взгляд, базовым понятием новой экономической концепции может стать иерархическая триада «экономический проиесс - экономическая система - экономическая среда» (см. рис.). Каждый элемент триады (процесс, систему или среду) будем называть структурой. На рисунке представлено функциональное взаимодействие процессов внутри системы (структура «экономическая система» на схеме детализирована), экономическая среда изображена как «черный ящик», она обменивается сигналами с экономической системой (внешнее взаимодействие структур). В реальности экономическая среда формируется в резуль-

${ }^{29}$ Клейнер Г.Б. 2011. Новая теория экономических систем и ее приложения. Вестник Российской академии наук. T. 81. № 9. C. 794-811.

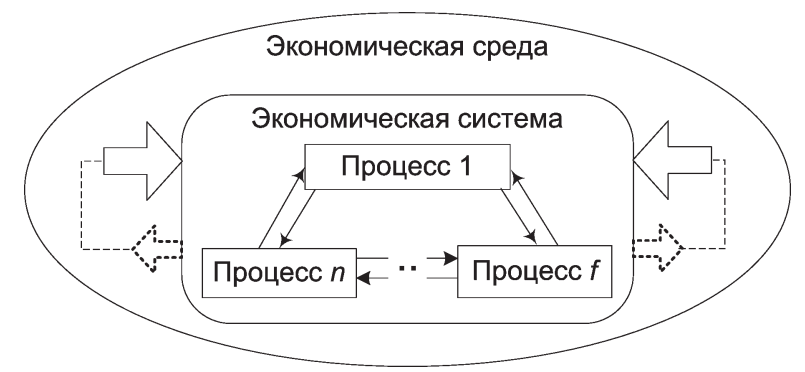

Модель иерархической триады «экономический процесс - экономическая система - экономическая среда»

Источник. Авторская разработка. тате взаимодействия сложных экономических систем, т. е. структура «экономическая среда» может быть конкретизирована по аналогии со структурой «экономическая система» на основе принципа универсальности и масштабируемости.

В предложенной модели иерархической триады можно через взаимодействие экономических факторов детализировать и структуру «экономический процесс». Поскольку аксиоматичным является тот факт, что любой экономический фактор не стационарен и может быть формализован функцией, изменяющейся во времени, т. е. по сути фактор сам является процессом, то конкретизация структуры «экономический процесс» нецелесообразна и избыточна. Таким образом, «экономический процесс» - нижний терминальный уровень триады.

Экономическое развитие обуславливают порождаемые взаимодействием внутренних и внешних факторов изменения спонтанных и необратимых процессов экономической системы в меняющейся экономической среде. Таким образом, изменения процессов с течением времени в результате внешних и внутренних взаимодействий позволяют интегрировать в экономическую триаду экономическую динамику. На рисунке экономическая динамика отражена в виде стрелок двух типов, отражающих внутреннее и внешнее взаимодействия ${ }^{30}$ структур одного и разных уровней соответственно. Любое взаимодействие приводит к изменению, т. е. к динамике.

Динамичны все элементы триады, но чем выше уровень иерархии, тем более явно проявляется свойство экономической инерционности структуры. Чем больше и сложнее экономическая структура, тем, во-первых, сложнее увеличить вероятность реакции структуры на сигналы (часто наблюдается корреляция вероятности отклика с увеличением количества сигналов или их мощности воздействия), во-вторых, дольше временной отклик на поступающие сигналы изменений (особенно внешние). На рисунке свойство экономической инерционности структуры отмечено стрелками

${ }_{30}$ Внутреннее и внешнее взаимодействия стилизованы на рисунке в виде одноконтурных и двухконтурных стрелок соответственно. 
внешнего взаимодействия разного контура и размера. Размер стрелки отражает силу или мощность воздействия. Контур стрелки характеризует влияние воздействия во временном аспекте: сплошным контуром стрелки изображено краткосрочное воздействие, а пунктиром - долгосрочное воздействие относительно рассматриваемого временного интервала моделирования экономической динамики. Стрелка большего размера сплошного контура отражает более мощный сигнал структуры внешнего уровня - его влияние на структуру внутреннего уровня крайне существенно, и отклик на него должен быть достаточно коротким. То есть экономическая система получает управляющие импульсы из экономической среды, оказывающие существенное влияние на моделируемую динамику системы в обозначенном временном интервале. Стрелка меньшего размера курсивного контура (обратная связь) отражает более слабый сигнал структуры внутреннего уровня, влияние которого на структуру внешнего уровня существенно, но отклик на сигнал (ввиду большей инерционности более сложной структуры) в реальности может иметь достаточно большой временной лаг от момента его входа. Если лаг отклика превосходит временной интервал моделирования динамики (что чаще всего в реальности и происходит), то в модели данным сигналом в явном виде можно пренебречь. Однако с точки зрения концептуального подхода к моделированию экономического развития сигналы обратной связи имеют исключительно важное значение. Во-первых, они отражают активность структуры нижнего уровня по отношению к структуре высшего уровня, в долгосрочной перспективе фактически формируя и меняя ее. Во-вторых, сигналы обратной связи отражают свойство интерактивности взаимодействия структур различных уровней, являясь фактически единым механизмом взаимовлияния и взаимного формирования, что на рисунке изображено курсивным соединением стрелок внешнего взаимодействия. Кроме того, это соединение отражает тот факт, что за достаточно длительный промежуток времени обратный сигнал способен оказать существенное влияние на регулирующий сигнал от среды к системе и модифицировать его, неявно присутствуя в модели экономической динамики, тем самым подтверждая доминирование экономической структуры верхнего уровня над экономической структурой внутреннего уровня триады только лишь на краткосрочном горизонте. В долгосрочной перспективе внутренние структуры и их взаимодействия меняют структуры внешнего уровня.

Согласно системной экономической теории, модель иерархической триады с интегрированной экономической динамикой реализует принципы взаимодействия экономических структур в пространстве и времени, отражая свойства универсальности, масштабируемости и динамизма цифровой трансформации.

C позиций новых доминирующих метафор институционального анализа представляет научный интерес использование концептуальных идей эволюционной биологии развития, согласно одной из которых следует отказаться от противопоставления микро- и макроанализа и развивать мезоинструменты анализа, позволяющие связать микро- и макроаспекты сложных систем (Фролов, 2019). В этом контексте именно процессно-системный подход (структура «экономическая система» в триаде) является универсальным для дальнейшего развития идей математического моделирования современной экономической динамики сложных экономических явлений.

Процессы автоматизации, цифровизации, цифровой трансформации, цифровой экономики раскрыты в работе через анализ особенностей инновационной экономической деятельности соответствующего этапа. Но если методология и инструментарий теории инноваций уже достаточно исследованы научным и практикующим экономическим сообществом, то сложные современные процессы цифровой трансформации требуют разработки новых научно-теоретических, методологических базисов, на основе которых будут формироваться актуальные концептуальные и инструментальные направления моделирова- 
ния. Новый базис предлагается синтезировать на основе ключевых концепций системного, кибернетического и институционально-эволюционного экономических направлений. Экономическая динамика является одним из аспектов экономического развития, которое обуславливают порождаемые взаимодействием внутренних и внешних факторов изменения процессов экономической системы в меняющейся экономической среде. Для разработки актуальных инструментов математического моделирования современной экономической динамики сложных экономических явлений цифровой трансформации предлагается концептуальная иерархическая модель триады «экономический процесс - экономическая система - экономическая среда». В дальнейших работах автор планирует развивать и детализировать предложенную модель экономической триады с интегрированной экономической динамикой как на логическом уровне, так и на уровне математической формализации.

\section{СПИСОК ЛИТЕРАТУРЫ (REFERENCES)}

Бухт Р., Хикс Р. 2018. Определение, концепция и измерение цифровой экономики. Вестник международных организаций: образование, наука, новая экономика. Т. 13. № 2. C. 143-172. [Bukht R., Heeks R. 2018. Defining, conceptualising and measuring the digital economy. Vestnik mezhdunarodnykh organizatsiy: obrazovanie, nauka, novaya ekonomika. Vol. 13. No 2. PP. 143-172. (In Russ.)]

Горев В.П., Макарова Г.Н., Сергеева С.В. (Ред.) 2008. Макроэкономика: актуальные направления и проблемы развития. Иркутск: Байкальский государственный университет. [Gorev V.P.,
Makarova G.N., Sergeeva S.V. (Eds.) 2008. Macroeconomics: Actual directions and problems of development. Irkutsk: Baykal'skiy gosudarstvennyy universitet. (In Russ.)]

Коуз Р. 1993. Фирма, рынок и право. Москва: Дело. [Coase R. 1993. The firm, the market and the law. Moscow: Delo. (In Russ.)]

Мясникович М., Глазьев С. 2020. Методологические подходы к разработке стратегии развития ЕАЭС в условиях мирового кризиса. $\mathrm{Ha}$ ука и инновации. № 6. С. 10-21. [Myasnikovich M., Glazyev S. 2020. Methodological approaches to the EAEU strategy development in a global crisis. Nauka i innovatsii. No 6. PP.10-21. (In Russ.)]

Нельсон Р., Уинтер С. 2000. Эволючионная теория экономических изменений. Москва: Финстатинформ. [Nelson R., Winter S. 2000. An Evolutionary Theory of Economic Change. Moscow: Finstatinform. (In Russ.)]

Норт Д. 1997. Институты, институциональные изменения и функиионирование экономики. Москва: Фонд экономической книги «Начала». [North D. 1997. Institutions, institutional change and economic performance. Moscow: Fond ekonomicheskoy knigi «Nachala». (In Russ.)]

Фролов Д.П. 2019. Эво-дево: парадигмальный вызов для институционально-эволюционного анализа. Экономическая наука современной России. № 2. C. 35-51. [Frolov D.P. 2019. Evo-devo: Paradigmal challenge for institutional-evolutionary analysis. Ekonomicheskaya nauka sovremennoy Rossii. No 2. PP. 35-51. (In Russ.)]

Хау Дж. 2012. Краудсорсинг: коллективный разум как инструмент развития бизнеса. Москва: Альпина Паблишер. [Howe J. 2012. Crowdsourcing: Why the Power of the Crowd Is Driving the Future of Business. Moscow: Al'pina Pablisher. (In Russ.)]

Kornai J. 1998. The System Paradigm. William Davidson Institute Working Papers No 278. Ann Arbor: The University of Michigan Press.

Tapscott D. 1995. The Digital Economy: Promise and Peril in the Age of Networked Intelligence. New York: McGraw-Hill. 
In citation: Belorusskiy Economicheskiy zhurnal. 2020. No 4. PP. 79-90.

Belarusian Economic Journal. 2020. No 4. PP. 79-90.

\title{
THEORETICAL AND CONCEPTUAL APPROACHES \\ TO ECONOMIC DYNAMICS MODELING TAILORED TO THE DIGITAL TRANSFORMATION
}

\author{
Olesia Poddubnaia ${ }^{1}$ \\ Authors affiliation: ${ }^{1}$ Belarusian State Economic University (Minsk, Belarus). \\ Corresponding author. Olesia Poddubnaia (poddubnaya.o@tut.by).
}

ABSTRACT. Based on current economic theories the article describes such concepts as «automatization», «digitalization», «digital transformation», «digital economy» and studies the links they establish. Algorithmically-digital paradigm of new economic relations is in the spotlight. Key features of digital resources and technologies are highlighted. By synthesizing current ideas of economic cybernetics, institutional and systemic approaches a scientific hypothesis «economic process - economic system - economic environment» hierarchical triad model is offered for consideration. Economic dynamics carved out by both external and internal interactions of processes in economic system is embedded in a hierarchical triad model as part of evolutionary economic theory. It also suggests further theoretical and methodological foundations for potential approaches to economic dynamics modeling under the digital transformation.

KEYWORDS: digitalization, digital transformation, digital economy, economical dynamics, institutionalevolutional concept.

JEL-code: B15, B16, C65, O10.

DOI: $10.46782 / 1818-4510-2020-4-79-90$

Received 24.11.2020 